UJBM, Vol. 2, No. 2, July - December 2003, pp 56-66

ISSN 0975-3311

https:/ / doi.org/ 10.12725/ ujbm.3.6

\title{
TEAM BUILDING - A TOOL FOR MANAGEMENT
}

\section{Sunaina Sridharan, Romate John** \&udha Bhogle***}

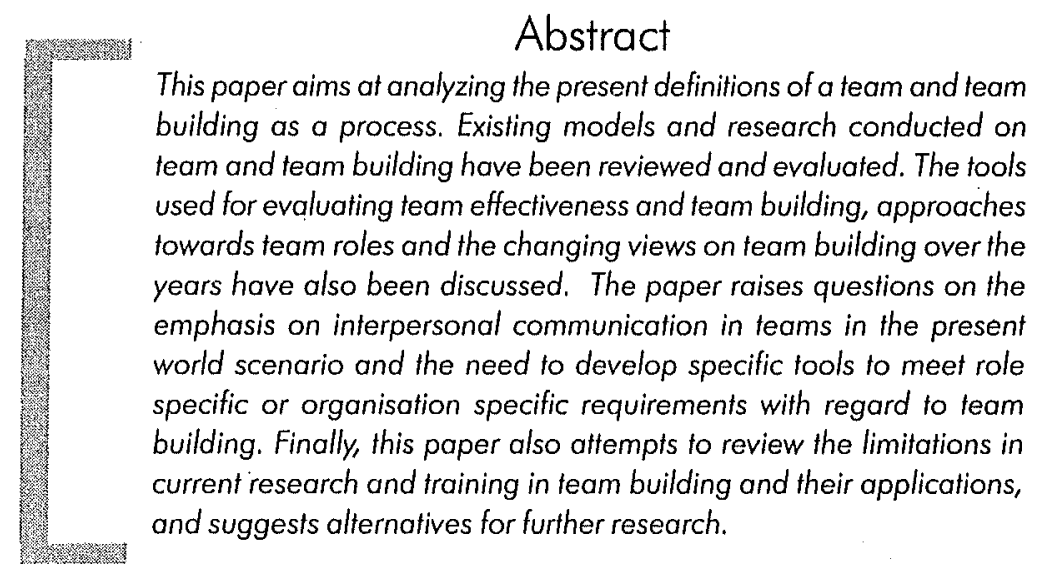

\section{Introduction}

The emergence of the idea of a 'team' can be traced back to the late 1920 s and early 1930s with the now classic Hawthorne Studies. These involved a series of

* Consultant Counselling Psychologist, Bangalore University.

** Counselling Psychologist, Bangalore University.

*** Professor, Department of Psychology \& Coordinator, Centre for Psychological Counselling, Bangalore University. 
research activities designed to examine in-depth what happened to a group of workers under various conditions. After much analysis, the researchers agreed that the most significant factor was the building of a sense of group identity, a feeling of social support and cohesion that came with increased worker interaction. These research findings spurred companies to seriously consider the idea of grouping their employees into effective work teams and to this day they are still important considerations for human resource developers (Dyer, 1990).

"Team building" grew out of the group dynamics area of social psychology, incorporating much of the theory and research in small groups as well as the applied focus used in training groups (T-groups), which were very strong in the 1950s and 1960s. During the late 1950s and early 1960s, management theory centered on the works of McGregor (1960), Likert (1961), and Blake and Mouton (1964). It has been said that one of the great breakthroughs of the 1950's was that management consultants became aware of management teams as entities. Since then, managers and Organizational Development professionals have devoted enormous efforts to develop healthy, effective teams and to help team-members work smoothly together (Luthans, 1995; Pfeiffer, 1996; Robbins, 1996).

Teams are an important element in the new high performance forms of organization. It is therefore important to understand what teams are and what they aren't, if they are to be used effectively.

Teams differ from committees, groups of co-workers, and other groups. Teams have performance goals to achieve and member of the teams feel mutually accountable for achieving them.

What is the definition of a team? A team is defined as a reasonably small group of people, who bring to the table a set of complementary and appropriate skills, and who hold themselves mutually accountable for achieving a clear and identifiable set of goals. Conceptually, a team can be viewed as a socially constructed phenomenon or linking mechanism that integrates individuals and organisations (Horvath, Callahan, Croswell \& Mukri, 1996). A team is thus a group of people working together towards a common goal.

\section{Team Effectiveness}

Team activities are a powerful vehicle for building skills. People learn skills from each other. They learn how other parts of the organization function. Teams serve to build up a repertoire of skills in the organization and this enhances the organization in the long tearm. 
An effective team must develop good synergy. When a group finally clicks and become a team, it will find creative ways to solve problems and come up with innovative solutions. In many situations, teams can achieve more than individuals working on their own. This is because teams can bring to bear a wider range of skills and experience to solve a problem. Teams also produce better quality decisions. Synergy comes about when gains from the feam setting exceed the losses. Synergy is effected by group interaction. It is also dependent upon the group size. A larger group has the potential to be able to provide a greater variety of skills. However, when the group is too large the individual contribution of each person decreases. A small size is better as it generates team spirit. The team should have just enough hands to do the work and no more.

Teams can have their shady side as well. They are not always effective. They can be highly dysfunctional. They can develop a 'group think' mentality that can produce bad decisions. They can be disruptive, leading to arguments and discord in the organization. They can be enormously wasteful of people's time and energy.

In short, teams can be good, but they can also be bad. In the new organization, teams have a critical role to play. Work teams are used as the basic unit of organization. Problem solving teams are used to improve the way the organization performs, and management teams are used to develop strategy and to drive the changes. If the role of teams is to be positive, people must learn how to make them work effectively.

What do we mean by team effectiveness? A team can be considered to be effective if their output is judged to meet or exceed the expectations of the people who receive the output. Producing a quality output is not enough to judge the effectiveness of the team. The second criterion is that the team should still be able function effectively after they have completed their task. It should not be torn apart by dissension. Finally, effectiveness is judged by whether the team feels satisfied with its efforts. If the team members are pleased with their efforts, if the experience has been a good one, if time spent on the project has been worth the effort, the team has likely been effective.

What then are the factors that contribute towards an effective team? There has been a great deal of research into the subject of team effectiveness over the last decade or so and there is a consensus on what factors must be controlled in order to set up and run effective teams.

There are three areas of group behaviour that must be addressed for teams to be effective: 
(i) The team must work hard. The effort that the team puts in to get the job done is dependent on whether the nature of the task motivates the members of the team and whether the goals are challenging, and are clearly defined. The job should require a variety of high-level skills to make it interesting. The task itself should be seen as being worthwhile. It needs to be a whole piece of work with a clear and visible outcome so that people can feel a sense of ownership. The job should provide the team with an opportunity for self-regulation. They should decide how the work is to be done. Goals provide a sense of direction to the team so that when conflict occurs it is possible to channel the conflict more constructively by returning to the goals for direction. During the eighties quality circles were the latest fad. They generally failed to achieve any worthwhile results because they were not focused on results. They were aimless. If goals are foggy or too easy to achieve, the team will not be motivated to make the extra effort that separates a high performance team from an ineffective group. Providing a challenging job is thus the most important motivator to sustain group effort. Goals need to be challenging, but not impossible to achieve. They also need to be measurable so that progress towards achieving them can be monitored and results confirmed.

Rewards are important. Rewards reinforce the motivational aspects of having a well-designed task and challenging goals. People tend to engage in those behaviours that are rewarded, so the rewards need to suit the personal characteristics of the people on the team. Whatever form the reward takes, it is important that group effort be recognised.

On the whole, having a worthwhile task to perform and having clear challenging goals to meet best sustain hard work and effort. Rewards merely reinforce these conditions for fostering group effort.

(ii) The team must have the right mix of skills to bring to the table. These skills include technical, problem solving and interpersonal skills. This requires a careful review of the job to determine what relevant skills are required and selecting staff so that the team has the right balance. Interpersonal skills are also important. This is not as obvious as it may sound. Most people do not listen well. Listening is much more than being quiet when someone else is talking. Active listening is required. Many people do not speak to the point but ramble on or go off at a tangent. Most people do not take criticism well and tend to be definsive about their own opinions.

When the group is new, it is likely that members will bring narrow skills learned in their old roles. They will need to develop broader skills for the new job. To ensure that this is done, training and coaching should be provided. 
(iii) The team must be able to develop appropriate approaches to problem solving. This depends on developing a plan of attack and using appropriate techniques for analysis. At the beginning of the team project it is important to develop a code of conduct for meetings. The team needs to agree on a set of rules to - ensure that their efforts are purposeful and that all members contribute to the work. The most critical rules pertain to attendance, open discussion, using an analytical approach, not pulling rank over other members, planning the work and sharing work assignments. This will ensure that the work is done well and done on time.

In summary, to ensure that the best possible set of skills and experience is brought to the task, able people should be selected on the basis of their relevant skills, and training or cooching should be provided to make up any skill deficiencies.

For the team to be able to develop an appropriate strategy, it must have a clear definition of the problem, know what resources it has available and the limits, and understand the expectations. It must then develop a problem-solving plan. When this does not happen, people are passive. Their skills and knowledge are not utilised and they waste their time.

\section{Modern Approaches to Team Building}

The traditional HRD prescription for developing work-team effectiveness has been labelled "team development" or "team building". Since the late 80 s and 90s, "Team Building" has been recognised by many companies as an important factor in providing a quality service and remaining competitive. Yet the term 'team building' can sometimes seem rather nebulous - people often know that they need it, but aren't quite sure what it is. "Team Building" is the process of enabling that group of people (the team) to reach their goal.

Perhaps the most significant change in the entire team-building concept in the present world scenario has been the increased emphasis on helping teams achieve results: get work done. There was so much attention paid in the early days to the relationships between people (Hawthorne, Mayo) that work matters were often neglected. Now in a team-building exercise, most team facilitators realise the importance of both how people are working together and how work is getting done. Both social processes and task processes are now accepted as important to team success (Dyer, 1984).

"Team Building" is the process of enabling that group of people to reach their goal. It is therefore a management issue, and the most effective form of team 
building is that undertaken as a form of management consultancy, rather than as pure training. In its simplest terms, the stages involved in team building are:

- To clarify the team goals

- To identify those issues which inhibit the team from reaching their goals

- To address those issues, remove the inhibitors and enable the goals to be achieved

The primary skills in this process are recognisingthe right issues, and tackling them in an appropriate way and an appropriate order.

To effectively help teams make work contributions, HRD professionals need to understand what is meant by performance. According to Sink, Tuttle \& DeVries, (1984) performance can be measured by at least seven causally related criteria: effectiveness, efficiency, quality, productivity, quality of work life, innovation, and profitability/budget ability. There are moreover four general approaches to teambuilding interventions: goal setting, interpersonal relations, role clarification, and problem solving (Druckman \& Biork, 1994; Sundstrom, DeMeuse \& Futrell, 1990). How a team performs depends on the management of two major factors: performance and process. The performance factor focuses on what results are expected of the team. It also deals with the structure of the team's tasks. The process factor focuses on how the team interacts in meetings and focuses on maintenance of the team. Team leadership revolves around team performance, while team synergy arises from team processes.

\section{Measuring Team Effectiveness (TE)}

Alongside the statistics to support the use of teams, there is concrete literature to support both social and task processes in groups, as evidenced in Hackman's (1990) framework of group effectiveness. This has been used to descriptively analyse various kinds of teams in different types of organizational settings. It lays out specific types of outcomes that should be included in measuring team effectiveness (Hackman, 1990 ) such as (a) the group's production of a high-quality product, be it a physical product, a decision, a plan, or other output, that is acceptable to those who receive or review it; (b) the continuing capability of members to work together in the future, that is not burning themselves out in producing their product; and (c) the team's contribution to the well-being and growth of its members, allowing members to learn new things and to help their personal needs be satisfied. For groups to attain such effectiveness, teams benefit from being set up right in the first place.... or 
having the initial conditions of group structure that promotes competent work on the task (Hackman, 1990, p. 10).

These structural features include (a) a task structure that is clear and consistent with a group's purpose and high on what Hackman calls motivating potential... the team has a meaningful piece of work to do, for which members share responsibility, and accountability and that provides opportunities for the team to learn. how well it is doing (p. 10); (b) group composition that provides an appropriate size and mix of talents and interpersonal skils needed for communication and co-ordination with one another; and (c) core norms that regulate member behaviour and promote co-ordination and continuous scanning of the performance situation and proactive planning of group performance strategies (p. 11). These initial conditions also include an organizational context that supports and reinforces excellence through its system of rewards, education, and information, and makes available expert coaching and consultation assistance regarding effort, knowledge and skills, and performance strategies (pp. 11-13).

\section{Assessment of Teams}

Researchers, while assessing teams, need to consider many variables. Team effectiveness may be measured by the outcomes of the teamwork. The stages of team development may be an indicator for assessing teams. The way in which a team functions, may also be observed. The roles played by various team members may provide a researcher some information as to the assessment of teams. Relationships in a team also play a crucial role in team assessment. Two types of relationships are most commonly addressed in teams:

a. Interpersonal - the relationships among people in a group (benefits include improved teamwork, trust, communication, collaboration, conflict resolution, shared leadership, etc.);

and

b. Intrapersonal - the relationships of people with themselves (benefits include improved self-concept, confidence, strategic or visionary leadership, willingness to take calculated risks, etc.).

\section{Facilitating Team Building}

HRD professionals in modern organizations now place great emphasis on facilitating team building on the premise that team building will improve team effectiveness, 
and that this facilitation will assist the team in accomplishing tasks as they learn about their team members. Furthermore, they would also learn about their team's strengths and weaknesses and where to focus their professional development activities. Team Building is based on Experiential Learning, which is founded more on the active doing rather than the passive being done to. In this way, people practice the very skills they are learning and are more likely to maintain their change back at work. Experience-based learning (action alone) becomes "experiential" when elements of reflection, transfer and support are added to the based experience (Adair, 1986; Drexler, Sibbet and Forrester, 1998; Fraser and Neville 1993; Katzenback and Morentzer, 1987).

In team building, the team is led through exercises, which bring the members to focus on their weakest areas and lay new groundwork for improving that weakness. As a side benefit the team is exposed to proper facilitation skills and interested team members will be encouraged to assist in the facilitation when appropriate. A team will be able to articulate its team's long term direction and how that fits within the overall organization, develop goals and objectives that move the organization toward its long term direction, and develop accountability with their team to improve task completion. Rajaratnam (1996)

\section{Need for Research in Team Building: Current Scenario}

Druckman and Bjork (1994) state that there is much enthusiasm for these approaches among practitioners and consultants, but it is not matched by strong empirical support for their effect on team performance (p. 125). Related theory and research has been limited. Dyer (1984) noted that models of team performance tend to focus only on limited factors that might influence performance and to exclude some potentially important factors. Further, most studies have examined group dynamics that were unrelated to performance or were conducted in a laboratory setting (Shea \& Guzzo, 1987). As a result, team studies have not greatly contributed to our understanding of how naturally forming teams in the workplace interact over time to produce outputs that contribute to an organization. Buller (1986) noted that the results of team-building research have been ambiguous for two primary reasons: Team building as a concept has not been well defined, and the research has been methodologically poor. Existing tools either assess teams in terms of team members or team functioning as a whole. Concurrent study of team members, team functioning, evaluation of team members by self, peers and the organisation have not been conducted. Therefore, these tools are not sufficient to assess teams in terms of role-specific or organization specific requirements.

Furthermore, the learning of the team members may be limited to the laboratory, and thus may be temporary. It could be that the team members behave or are 
trained to behave in a certain way due to social modelling or as a result of practice or compulsion. There are no studies to evaluate the transfer of this learning to the workplace and monitoring of the same or to show that these changes reinforce everyday life at work. Therefore, self-monitoring may be necessary, and tools specifically designed to do the same need to be developed.

Team building can also take a different form depending on the size and nature of the team. In a project environment, where team composition is continually changing, the emphasis must be on developing the skills in individuals to be effective feam members.

In conclusion a multidimensional approach may be the need of the hour. Research on team building and team effectiveness may have to be conducted where every member of the team is assessed and evaluated from different directions: by himself (self), by his peers, (peer evaluation), by the team leader and outside observers. This may be required because a team member may feel that he is contributing to the team and is an important part of the team, whereas his team members do not evaluate him in a similar way. Thus self and peer evaluations may show discrepancies, which themselves may be indicative of team ineffectiveness. This paper therefore attempts to question whether there is need for further research to bridge this gap between subjective evaluations and evaluations by others. Further, in the Indian politico-social system, it may be necessary to consider team membership and its effectiveness taking into consideration their religio-socio cultural differences.

\section{References}

1. Adair, J. (1986). Effective Team Building, Calcutta: Rupa and Co.

2. Blake, R. and Mouton, J. (1964). The Managerial Grid, Houston: Gulf.

3. Buller, P.F. (1986) The Team building-task performance relation: Some conceptual and methodological refinements. Group \& Organizational Studies, Vol. 11, pp. 147-168.

4. Drexler, A.B., Sibbet, D., and Forrester, R.H. (1998). The Team Performance Model. In W.B Reddy and K Jammison (Eds) Team Building: Blueprints for Productivity and Satisfaction ( $p p$ 45-61). Alexandria, Virginia, NTL Institute for Applied Behavioral Science and San Diego, California, University Associates (copublishers)

5. Druckman, D. and Biork, R.A. (Eds.) (1994). Learning, remembering, believing: Enhancing human performance. Washington, DC: National Academy Press. 
6. Dyer, J.L. (1984) Team research and team training: A state-of-the-art review. Human Factors Review, pp. 285-319.

7. Fraser, A. and Neville, S. (1993). Team Building: A practical guide. New Delhi: Sterling Publishers.

8. Hackman, J.R. (Ed) (1990). Groups that work (and those that don't): Creating conditions for effective teamwork. San Francisco: Jossey-Bass.

9. Horvath, L., Callahan, J.L., Croswell, C. and Mukri, G. (1996). Team sensemaking: An imperative for individual and organizational learning. In $E$. Holton (Ed.), Proceedings of the Academy of Human Resource Development, (pp. 415-421).

10. Katzenback J.R. and Morentzer, A. (1987). A new model of team building: A technology for today and tomorrow. In J.W. Pfeiffer (Ed) The 1987 Annual: Developing human resources. (pp 255-268). San Diego, California, University Associates.

11. Likert, R. (1961) New Patterns of Management, New York: McGraw-Hill.

12. Luthans, F. (1995) Organizational Behaviour (7th edition). New York, McGraw-Hill Inc.

13. Mayo, E. (1933). The Human Problems of an Industrial Civilization, Division of Research, Graduate School of Business Administration, Harvard University.

14. McGregor, D. (1960). The Human Side of Enterprise, New York: McGraw-Hill.

15. Pfeiffer, J.W. (1996) Theories and Models in Applied Behavioral Science, Nol 2). San Diego, California. Pfeiffer and Company.

16. Rajaratnam, S. (1996). Team Building intervention for organization development under different organizational contextual conditions. Hyderabad: Academy of HRD (mimeo)

17. Robbins, S.P. (1996). Organizational Behaviour: Concepts, Controversies and Applications, (7th edition). New Delhi: Prentice-Hall of India.

18. Russ-Eft, D, Preskill, H., and Sleezer, C., (1997). Human Resource Development Review: Research and Implications. London: Sage

19. Shea, G.P. and Guzzo, R.A. (1987). Group effectiveness: What really matters? Sloan Management Review, Vol. 28, pp. 25-31. 
20. Sink, D.S., Tuttle, T.C., and DeVries, S.J. (1984). Productivity measurement and evaluation: What is available? National Productivity Review, Vol. 3, pp. 265-287.

21. Sundstrom, E., DeMeuse, K.P. and Futrell, D. (1990). Work teams: Applications and effectiveness. American Psychologist, 45 (2), pp. 120-133.

22. Tuckman, B.W. and Jensen, M.A. (1977). Stages of small group development revisited, Group and Organizational Studies, 2(4), 419-427. 